\title{
Tracking control of parallel manipulator with 3-DOF
}

\author{
Gaurav Chaudhary" and Jyoti Ohri \\ Department of Electrical Engineering, NIT, Kurukshetra, India
}

(C)2016 ACCENTS

\begin{abstract}
A parallel three degrees of freedom (3-DOF) manipulator known as Maryland manipulator is considered in this paper. The manipulator model considered in this paper is more practical because the offset lengths are not taken zero. The trajectory tracking control of the Maryland manipulator is done using linear-quadratic regulator (LQR) based proportional-integral-derivative (PID) controller. Three sequential trajectories are used to provide complete dynamic analysis of the manipulator. The manipulator considered here is more practical because the offset lengths are not taken zero unlike previous research articles. The motivation behind using PID controller is its simplicity and effectiveness. The manipulator is a highly coupled and nonlinear system so the correct determination of control signal is very important to achieve good tracking performance. The process for selecting the PID parameters is discussed in detail and the simulations results are used to show the efficacy of the controller.
\end{abstract}

\section{Keywords}

Manipulators, Parallel robots, Inverse kinematics, PID, Robot control.

\section{Introduction}

A manipulator is fundamentally a reprogrammable, multifunctional mechanical arm intended to move parts, tools, and specialized device through preprogrammed motions for the performance of various tasks. With the advances in technology over last decades Parallel manipulator became more popular for industrial purpose. Parallel manipulators are used for variety of tasks such as flight simulator [1], medical tools [2-4], pick and place operations. The kinematics of parallel manipulator differs from serial manipulator.

Parallel manipulator consists of two platforms one of which is fixed and another is moving platform. These two platforms are connected to each other with the help of limbs. These limbs may consist of revolute or translational joints. Each limb is driven individually. Such type of structure results in closed kinematic mechanism. The kinematic analysis of parallel manipulator is difficult and it has been focus of many researchers [5-8]. The trajectory control of parallel mechanism like this present unique challenges because the dynamics of parallel manipulator are highly coupled and nonlinear. The precision depends on the accuracy of each actuator as well as on the synchronization of the actuators.

*Author for correspondence
Over last few decades many new algorithm are proposed for tracking control but none of them match with PID controller in terms of simplicity and ease of implementation. Zeigler-Nichols proposed an experimental method for tuning of PID controller; though this method has some limitations still it is widely used. In [9] tuning of PID controller is done which is quite similar to $\mathrm{ZN}$ method. A fair analysis is done by [10] between different methods of PID controller tuning. In [11], tuning method of PID controller had proposed using gain and phase margin specifications. In [12] authors have discussed a number of PID tuning methods. In [13] author has discussed PID tuning methods categorically.

In [14] had given a complete overview of modern PID tuning methods, different software packages of PID tuner and patents on PID tuning. In [15] authors have given a method for pole placements using PID controllers. In [16] authors proposed a method for tuning of fuzzy based PID controller. In [17] authors have presented an approach for genetically tuning of PID controller. In last few decades researchers have focused on optimal control theory and formulated the well-known optimal state feedback controller known as linear quadratic regulator, this approach reduces the deviation in state trajectories of a system maintaining minimum control effort. A very detailed study of optimal control is presented in [18]. To get the optimal control signal algebraic Riccati equation 
is solved to obtain the transformation matrix $\mathrm{P}$ between State and co-state equations of system. The weighting matrices play a crucial role in the solution of control signal. For different weighting matrices the LQR will provide different control signal. In [19] authors proposed a method for tuning of PID controller using LQR approach.

The contribution of this paper is to determine the control action with the help PID controller. The precise and exact control action has great significance for trajectory tracking control of parallel manipulator which presents exclusive challenges.

This paper is organized as follows. System description of Maryland manipulator is presented in section 2. Section 3 presents the parallel manipulator mechanism and motor dynamic model developed by Tsai and Stamper. In section 4 the control strategy is explained in detail. Simulation results of trajectory tracking are shown in section 5 followed by the conclusion in section 6 .

\section{System description}

The manipulator presented here is a 3-DOF parallel manipulator developed by Tsai and Stamper [21] shown in Figure 1. The complete schematic diagram of Maryland manipulator is shown in Figure 2. It consists of fixed base and a moving platform and three similar limbs which connects the moving platform to the fixed base. Each limb contains two links which are input link and a four bar parallelogram passive link.

The platforms and links are connected to each other through the help of revolute joints. Four parallelogram structures also contain four revolute joints. The presented manipulator has only three degree of freedom since it has three input links which can drive the moving platform effectively in three directions which can be given as $\mathrm{X}, \mathrm{Y}$ and $\mathrm{Z}$ in Cartesian coordinate system.

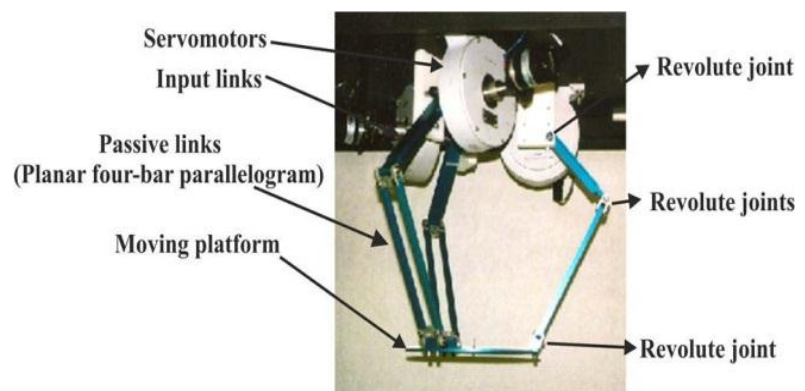

Figure 1 University of Maryland manipulator

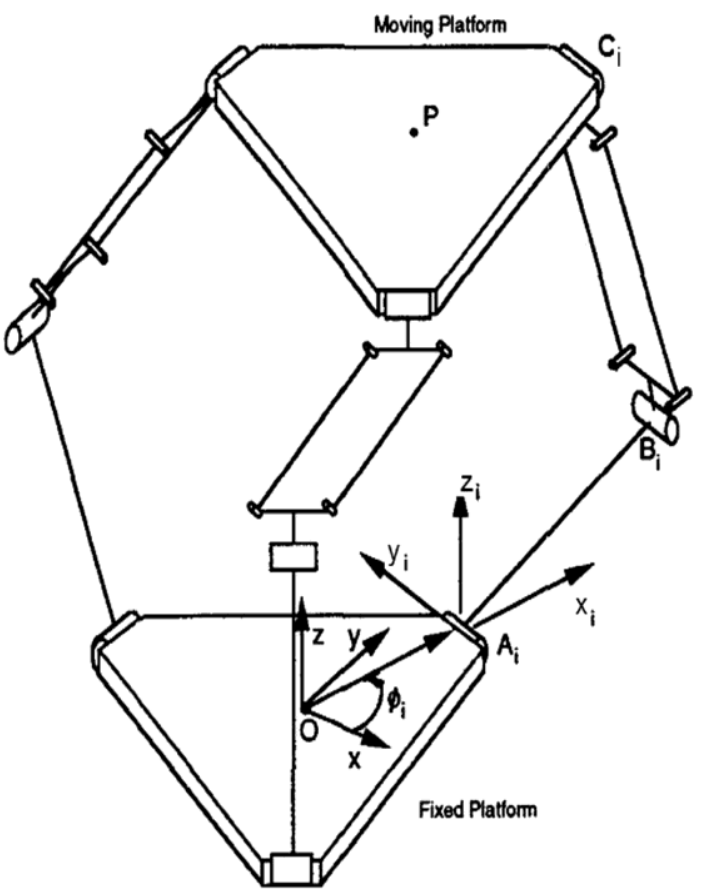

Figure 2 Schematic diagram of manipulator

\section{Mathematical model of Maryland manipulator}

A complete description of joint angles is given in Figure 3. The manipulator parameters are tabulated in Table 1. The head of fixed platform is represented by point $A_{i}(i=1,2,3)$. Let the reference coordinate system be $(x, y, z)$, for the purpose of examination, has its origin at the center of the base platform $O$ and the $x-y$ axes lies on the base platform and the $z$ axis is perpendicular to the platform. The center $P$ of the moving platform coincides with the origin of the reference frame. The coordinate system attached to fixed platform $A_{i}$ is $\left(x_{i}, y_{i}, z_{i}\right)$, such that the axis $\mathrm{x}_{\mathrm{i}}$ is lengthways the stretched line of $O A_{i}$, axis $y_{i}$ is lengthways the revolute joint axis at $A_{i}$. The manipulator parameters such as $\theta_{1 i}, \theta_{2 i}, \theta_{3 i}$ can be computed using inverse kinematic problem. Inverse kinematic problem refers to finding the joint variables corresponding to the desired trajectory of the moving platform given in task space using kinematic equation. The inverse kinematic problem can be solved with the help of following set of equations (1) and (2).

A special case has been considered for manipulator by taking the offset length zero [20]. In this paper the similar tracking problem is solved without taking the offset length zero. 


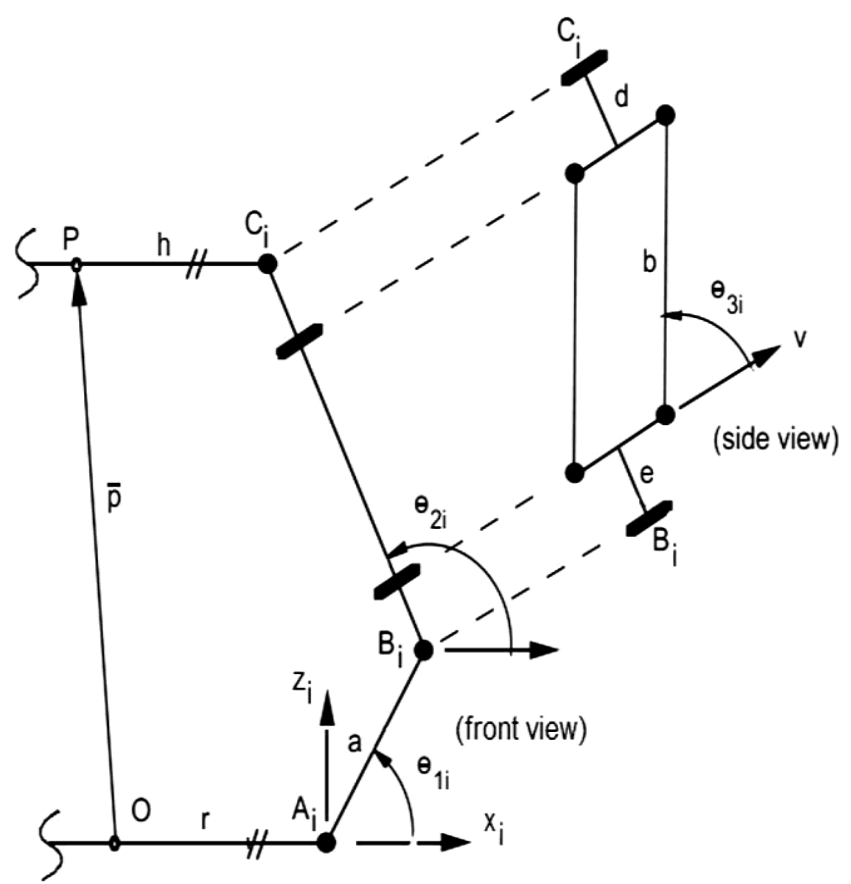

Figure 3 Description of joint angle

$$
\begin{aligned}
& {\left[\begin{array}{c}
\operatorname{acos}\left(\Theta_{1 i}\right)+\left(d+e+b \sin \left(\Theta_{3 i}\right)\right) \cos \left(\Theta_{1 i}+\theta_{2 i}\right) \\
b \cos \left(\Theta_{3 i}\right) \\
\operatorname{asin}\left(\Theta_{1 i}\right)+\left(d+e+b \sin \left(\Theta_{3 i}\right)\right) \sin \left(\Theta_{1 i}+\theta_{2 i}\right)
\end{array}\right]} \\
& =\left[\begin{array}{l}
c_{x i} \\
c_{y i} \\
c_{z i}
\end{array}\right]
\end{aligned}
$$

where

$\left[\begin{array}{c}c_{x i} \\ c_{y i} \\ c_{z i}\end{array}\right]=\left[\begin{array}{ccc}\cos \left(\emptyset_{\mathrm{i}}\right) & \sin \left(\emptyset_{\mathrm{i}}\right) & 0 \\ -\sin \left(\emptyset_{\mathrm{i}}\right) & \cos \left(\emptyset_{\mathrm{i}}\right) & 0 \\ 0 & 0 & 1\end{array}\right]\left[\begin{array}{c}p_{x} \\ p_{y} \\ p_{z}\end{array}\right]+\left[\begin{array}{c}h-r \\ 0 \\ 0\end{array}\right]$

Equation (2) represents the position of point $C_{i}$ with respect to coordinate frame $\left(x_{i}, y_{i}, z_{i}\right)$, and $p_{x}, p_{y}, p_{z}$ are the desired coordinate of the moving platform with in the workspace of manipulator.

By solving the second row of (1) two solution of $\theta_{3 i}$ can be obtained as given in (3)

$\theta_{3 i}= \pm \cos ^{-1}\left(\frac{c_{y i}}{b}\right)$

Similarly $\theta_{2 i}$ can be found by using the (4)

$$
\theta_{2 i}= \pm \cos ^{-1}(k)
$$

where

$k=\left(c_{x i}{ }^{2}+c_{y i}{ }^{2}+c_{z i}{ }^{2}-a^{2}-b^{2} \cos \left(\theta_{3 i}\right)-\right.$

$\left.\left(d+e+b \sin \left(\theta_{3 i}\right)\right)\right) /(2 \mathrm{a}(\mathrm{d}+\mathrm{e}+$ $\left.\operatorname{bsin}\left(\theta_{3 i}\right)\right)$
Corresponding to each solution of $\theta_{2 i}, \theta_{3 i},(2)$ yields a unique solution for $\theta_{1 i}$ which can be given by (5)

$\theta_{1 i}= \pm \cos ^{-1}\left(\frac{c_{z i} k_{2}+c_{x i} k_{1}}{k_{1}{ }^{2}+k_{2}{ }^{2}}\right)$

where

$k_{1}=a+b \sin \left(\theta_{3 i}\right) \cos \left(\theta_{2 i}\right)+(d+e) \cos \left(\theta_{2 i}\right)$

\begin{tabular}{|c|c|c|}
\hline Symbol & Description & Value \\
\hline$\theta_{1 i}$ & $\begin{array}{l}\text { Actuator angle } \\
\text { measured from } \\
x_{i} \text { axis to } A_{i} B_{i}\end{array}$ & $\begin{array}{l}\text { Find inverse } \\
\text { kinematic (rad) }\end{array}$ \\
\hline$\theta_{2 i}$ & $\begin{array}{l}\text { Passive angle is } \\
\text { defined from the } \\
\text { extended line of } \\
A_{i} B_{i} \text { to the line } \\
\text { defined by the } \\
\text { intersection of } \\
\text { the plane of the } \\
\text { parallelogram } \\
\text { and the } x_{i}-z_{i} \\
\text { plane }\end{array}$ & $\begin{array}{l}\text { Find inverse } \\
\text { kinematic (rad) }\end{array}$ \\
\hline$\theta_{3 i}$ & $\begin{array}{l}\text { Passive angle is } \\
\text { measured from } \\
\text { the } y_{i} \text { direction to } \\
B_{i} C_{i}\end{array}$ & $\begin{array}{l}\text { Find inverse } \\
\text { kinematic (rad) }\end{array}$ \\
\hline$\emptyset_{1 i}$ & $\begin{array}{l}\text { Angle is } \\
\text { measured from } \\
\text { the x-axis to the } \\
x_{i} \text {-axis and is a } \\
\text { constant } \\
\text { parameter of the } \\
\text { manipulator } \\
\text { design }\end{array}$ & {$[0,120,240](\mathrm{deg})$} \\
\hline $\mathrm{a}$ & $\begin{array}{l}\text { Length of links } \\
A_{i} B_{i}\end{array}$ & $203.2 \mathrm{~mm}$ \\
\hline b & $\begin{array}{l}\text { Length of links } \\
B_{i} C_{i}\end{array}$ & $254.0 \mathrm{~mm}$ \\
\hline$e, d$ & $\begin{array}{l}\text { Small offset } \\
\text { length of in } \\
\text { parallelogram }\end{array}$ & $0.0159 \mathrm{~mm}$ \\
\hline $\mathrm{r}$ & $\begin{array}{l}\text { Radius of fixed } \\
\text { platform }\end{array}$ & $127.0 \mathrm{~mm}$ \\
\hline $\mathrm{h}$ & $\begin{array}{l}\text { Radius of moving } \\
\text { platform }\end{array}$ & $127.0 \mathrm{~mm}$ \\
\hline$m_{a}$ & $\begin{array}{l}\text { Mass of input } \\
\text { link }\end{array}$ & $0.184 \mathrm{~kg}$ \\
\hline$m_{b}$ & $\begin{array}{l}\text { Mass of the one } \\
\text { of the two } \\
\text { connecting road }\end{array}$ & $0.085 \mathrm{~kg}$ \\
\hline$m_{p}$ & $\begin{array}{l}\text { Mass of the } \\
\text { moving platform }\end{array}$ & $0.413 \mathrm{~kg}$ \\
\hline$I_{m}$ & $\begin{array}{l}\text { Axial moment of } \\
\text { inertia of the } \\
\text { rotor mounted on } \\
\text { ith limb }\end{array}$ & 0.00434 N.m.s ${ }^{2}$ \\
\hline
\end{tabular}

$k_{2}=b \sin \left(\theta_{3 i}\right) \sin \left(\theta_{2 i}\right)+(d+e) \sin \left(\theta_{2 i}\right)$

Table 1 Parameters for manipulator 
Lagrangian approach is used here to obtain the equation of motion which describes the actuating torques. The motivation behind using the Lagrangian approach is the complex kinematics of manipulator. We take the assumption, as proposed by Tsai [21], that the mass of each rod, $\mathrm{m}_{\mathrm{b}}$, is evenly divide and concentrated at two end points $\mathrm{B}_{\mathrm{i}}, \mathrm{C}_{\mathrm{i}}$, to simplify the analysis.

As proposed by [20] the total kinetic energy of system is:

$T=\frac{1}{2} m_{p}\left(\dot{p_{x}}{ }^{2}+{\dot{p_{y}}}^{2}+{\dot{p_{z}}}^{2}\right)+\frac{1}{2}\left(I_{m}+\frac{1}{3} m_{a} a^{2}\right){\dot{\theta_{1 \iota}}}^{2}$

$+\frac{1}{2} m_{b}\left(\dot{p_{x}}{ }^{2}+{\dot{p_{y}}}^{2}+{\dot{p_{z}}}^{2}\right)+\frac{1}{2} m_{b} a^{2}{\dot{\theta_{1 \imath}}}^{2}$

The total potential energy of the system is given as

$$
\begin{array}{r}
P=m_{p} g_{c} p_{z}+\frac{1}{2} m_{a} g_{c} \operatorname{asin}\left(\theta_{1 i}\right) \\
+m_{b} g_{c}\left(p_{z}+\operatorname{asin}\left(\theta_{1 i}\right)\right)
\end{array}
$$

The Lagrangian equation of motion is given as

$\frac{d}{d t}\left(\frac{\partial L}{\partial q_{i}}\right)-\frac{\partial L}{\partial q_{i}}+\sum_{k=1}^{3} \lambda_{k} \frac{\partial \Gamma_{i}}{\partial q_{i}}=Q_{i}$ for $i=1$ to 6

where

$j=$ is the constraint index, $i=$ is the generalized coordinate index,

$k=$ is the number of constrained function,

$L=$ is the Lagrange function, where $L=T-P$,

$T=$ is the total kinetic energy of system,

$P=$ total potential energy of system,

$q_{i}=$ is the $i^{t h}$ generalized coordinate,

$Q_{i}=$ is a generalized external force,

$\partial q_{i}=$ is the $i^{t h}$ generalized coordinate,

$\lambda=$ is the Lagrange multiplier,

$\Gamma_{i}=$ is a constraint equation,

The constraint equation used to find the solution of Lagrangian equation of motion using the fact that the distance between joints B and C is constantly same as the length of the upper linking arm, b; that is

$$
\Gamma_{k}=\mathrm{B}_{\mathrm{i}} \mathrm{C}_{\mathrm{i}}^{2}-\mathrm{b}^{2}=0
$$

The desired trajectory tracking control can be accomplished by applying the torques, computed with the help of above given set of equations, to the input link of the each limb. The torque required is generated with help of three direct current motors (DC Motor).

The general block diagram structure for independent joint control is shown in Figure 4.

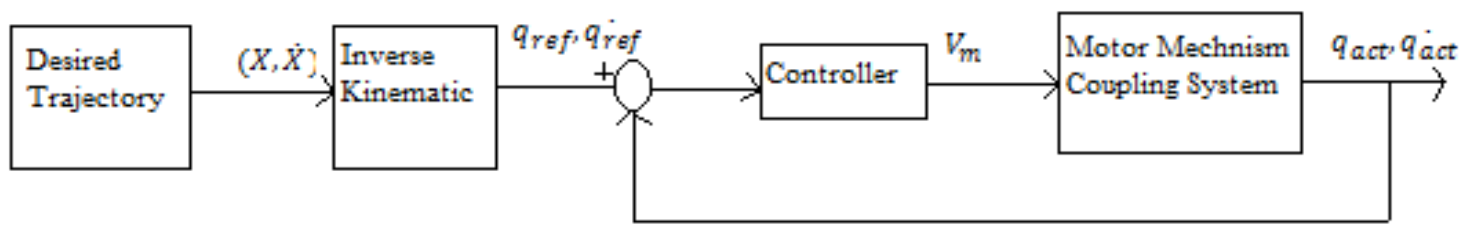

Figure 4 Block scheme of general independent joint control.

A DC motor is used for generating the required torque. The output of motor is proportionate to the input voltage applied to DC motor by the controller. The controller produces the input voltage such that the error i.e. $e=q_{\text {ref }}-q_{\text {act }}$ tend to zero. The type of controller applied is PID controller whose tuning approaches are discussed in detail in subsequent section.

$q_{\text {ref }}=$ desired input link angle in radian

$q_{a c t}=$ actual input link angle in radian

\section{Control strategy}

The control strategy used for trajectory tracking control is LQR based PID controller. The weight matrices of LQR is selected by trial and error method. In the presents approach we assume that the error, the integral of error and derivative of it are the state variables and designs the optimal state feedback controller gains as the PID controller parameters. In Figure 5 if the system is excited with an external input say $r(t)$ to have a control signal $u(t)$ and the system output $\mathrm{y}(\mathrm{t})$, then the system state variable defined as:

$\mathrm{x}_{1=} \int e(t) d t, \mathrm{x}_{2}=\mathrm{e}(\mathrm{t}), \mathrm{x}_{3}=\frac{d e(t)}{d t}$

From the Figure 2, it is clear that

$\frac{Y(s)}{U(s)}=\frac{K}{S^{2}+2 \zeta \omega_{n} S+\omega \mathrm{n}^{2}}=-\frac{E(s)}{U(S)}$ 


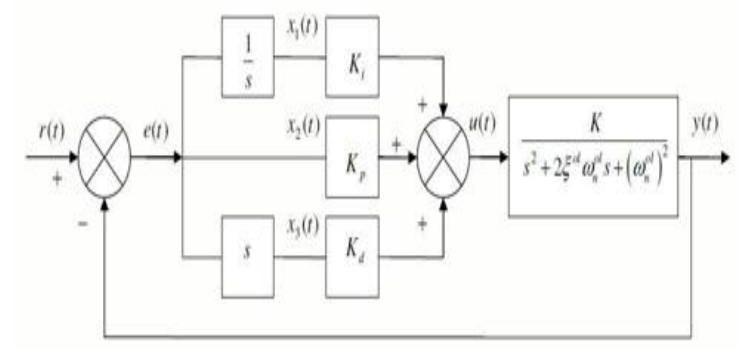

Figure $5 \mathrm{LQR}$ formulation of PID controller

The tracking problem is converted to regulator problem by making $r(t)=0$. So when there is no change in the set point equation (10) can be written as

$\left[\mathrm{s}^{2}+2 \zeta \omega_{n} \mathrm{~s}+\omega_{n}^{2}\right] E(s)=-K U(S)$

$\ddot{e}+2 \zeta \omega_{n} \dot{e}+\omega_{n}^{2} \mathrm{e}=-k u$

Using equation (9) and (12) we can write

$\dot{x_{3}}+2 \zeta \omega_{n} x_{3}+\omega_{n}^{2} x_{2}=-k u$

Using equation (9) and (13) the state space model is given as:

$\left[\begin{array}{c}\dot{x_{1}} \\ \dot{x_{2}} \\ \dot{x_{3}}\end{array}\right]=\left[\begin{array}{ccc}0 & 1 & 0 \\ 0 & 0 & 1 \\ 0 & -\omega_{n}^{2} & -2 \zeta \omega_{n}\end{array}\right]\left[\begin{array}{l}x_{1} \\ x_{2} \\ x_{3}\end{array}\right]+\left[\begin{array}{c}0 \\ 0 \\ -k\end{array}\right] \mathrm{u}$

From given state space model the system matrices given as:

$\mathrm{A}=\left[\begin{array}{ccc}0 & 1 & 0 \\ 0 & 0 & 1 \\ 0 & -\omega_{n}^{2} & -2 \zeta \omega_{n}\end{array}\right], \quad \mathrm{B}=\left[\begin{array}{c}0 \\ 0 \\ -k\end{array}\right]$

The quadratic cost function to be minimized for the LQR formulation of the system given by following equation:

$\int_{0}^{\infty}\left[x^{T}(t) Q x(t)+u^{T}(t) R u(t)\right] d t$

The minimization of cost function gives the state feedback control signal as:

$u(t)=-R^{-1} B^{T} P x(t)=-k x(t)$

Where $\mathrm{P}$ is the symmetric positive definite matrix obtained by solving the continuous algebraic Riccati Equation (CARE) given by

$A^{T} P+P A-P B R^{-1} B^{T} P+Q=0$

Here, the weight matrix $Q$ is a positive symmetric semi-definite and the weight factor $\mathrm{R}$ is positive integer. The selection of $\mathrm{Q}$ and $\mathrm{R}$ matrices is done by
Trial and Error, generally $\mathrm{R}$ is kept fixed and $\mathrm{Q}$ matrix is varied.

$\mathrm{P}$ and $\mathrm{Q}$ are given by:

$$
\mathrm{P}=\left[\begin{array}{lll}
P_{11} & P_{12} & P_{13} \\
P_{12} & P_{22} & P_{23} \\
P_{13} & P_{23} & P_{33}
\end{array}\right], \mathrm{Q}=\left[\begin{array}{ccc}
Q_{1} & 0 & 0 \\
0 & Q_{2} & 0 \\
0 & 0 & Q_{3}
\end{array}\right]
$$

Now let the unique solution of the CARE (17) be $P$, so the control signal corresponding to the solution of Algebraic Riccati Equation is given by:

$$
\begin{aligned}
& u=-K x(t)=-R^{-1}\left[\begin{array}{lll}
0 & 0 & -k
\end{array}\right]\left[\begin{array}{lll}
P_{11} & P_{12} & P_{13} \\
P_{12} & P_{22} & P_{23} \\
P_{13} & P_{23} & P_{33}
\end{array}\right]\left[\begin{array}{l}
x_{1} \\
x_{2} \\
x_{3}
\end{array}\right] \\
& \mathrm{u}=R^{-1} \mathrm{k}\left[\begin{array}{lll}
P_{13} & P_{23} & P_{33}
\end{array}\right]\left[\begin{array}{l}
x_{1} \\
x_{2} \\
x_{3}
\end{array}\right] \\
& u=\left[\begin{array}{lll}
K_{i} & K_{p} & K_{d}
\end{array}\right]\left[\begin{array}{l}
x_{1} \\
x_{2} \\
x_{3}
\end{array}\right] \\
& u=K_{i} \int e(t) d t+K_{p} e(t) d t+K_{d} \frac{d e(t)}{d t}
\end{aligned}
$$

The above given formulation shows that with the appropriate choice of $\mathrm{Q}$ and $\mathrm{R}$ matrices a PID controller can be tuned and so tuned PID controller will provide minimum state deviation with minimum control effort and better steady state response.

\section{Simulation}

The proposed methods for controlling the manipulator are tested using MATLAB simulations. The required torque is produced using DC motor. To validate the presented control approaches we have used three sequential trajectories which are given as follows:

$$
\left.\begin{array}{c}
\left.\begin{array}{c}
p_{x}=0 \\
p_{y}=0 \\
p_{z}=0.35+\frac{t^{2}}{100}
\end{array}\right\} \text { if } \mathrm{t} \leq 5 \\
p_{x}=0.06 \cos (t) \\
p_{y}=0.06 \sin (t) \\
p_{z}=0.35 \\
p_{x}=0 \\
p_{y}=0 \\
p_{z}=0.35-\frac{t^{2}}{100}
\end{array}\right\} \text { if } 5<\mathrm{t} \leq 10
$$

The graphical representation of the each three axis with respect to time is given in Figure 6.

The graphical representation of input link angle (radian), obtained solving the inverse kinematic problem, of first limb is shown in Figure 7. 


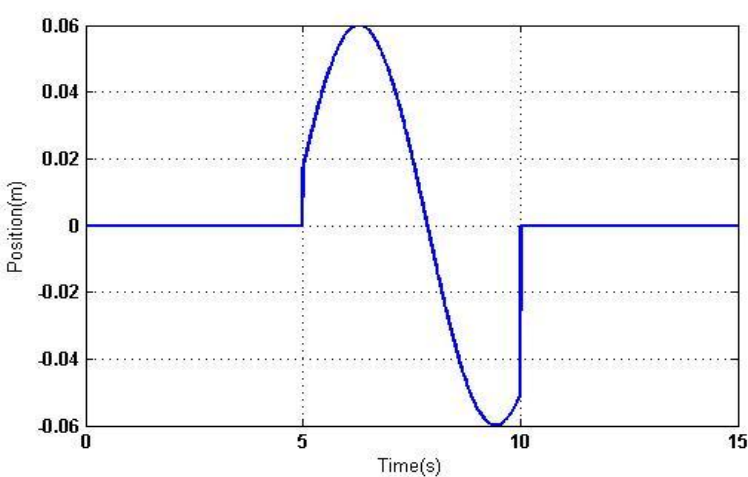

(a)

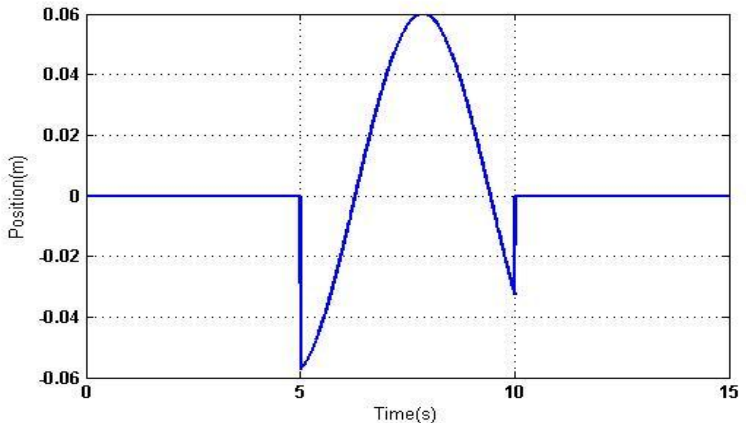

(b)

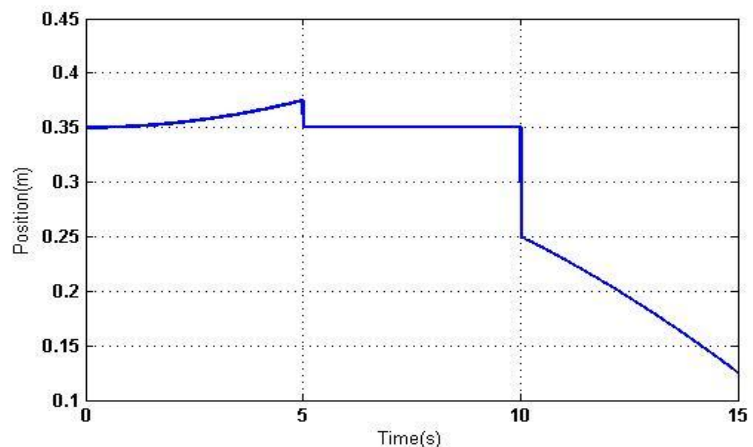

(c)

Figure 6 Graphical representation of three trajectories for three axis. (a) $\mathrm{x}$-axis (b) y-axis (c) zaxis

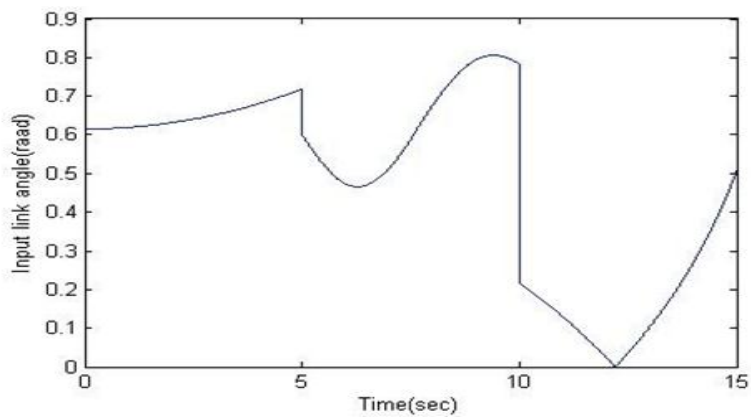

Figure 7 Desired input link angle corresponding to first limb
The motor can be modeled as simply relating torque equation with the voltage equation. The gain of the motor under such case is taken as $0.99 \mathrm{~N} . \mathrm{m} /$ volt. The generated torque is applied to single link dynamic model which can be obtained by linearization of the dynamics of manipulator. This model is based on the assumption that each link can be modeled separately; it implies that the motion of the rest of the manipulator does not influence the input link that is being modeled. The single link dynamic model obtained is given as follows:

$\frac{\theta_{11}}{\tau_{11}}=\frac{1}{\alpha s^{2}+c_{d} s+\beta \sin (\pi / 4)}$

Where

$\alpha=I_{m}+\frac{1}{3} m_{a} a^{2}+m_{e q} a^{2}$

$\beta=a g\left(\frac{1}{2} m_{a}+m_{e q}\right)$

$m_{e q}=2 m_{b}+\frac{1}{3} m_{c}$

After implementing the general block diagram scheme as shown in Figure 4, using the above discussed control approaches, the results obtained are as following. The weight matrices selected are as following.

$Q=\left[\begin{array}{lll}1 & 0 & 0 \\ 0 & 1 & 0 \\ 0 & 0 & 1\end{array}\right], \quad R=[0.01]$

The closed loop response of the system is shown in the Figure 8 . The results are obtained by using linear simulation in MATLAB. It can be seen that there are no overshoots in case of LQR based PID controller.

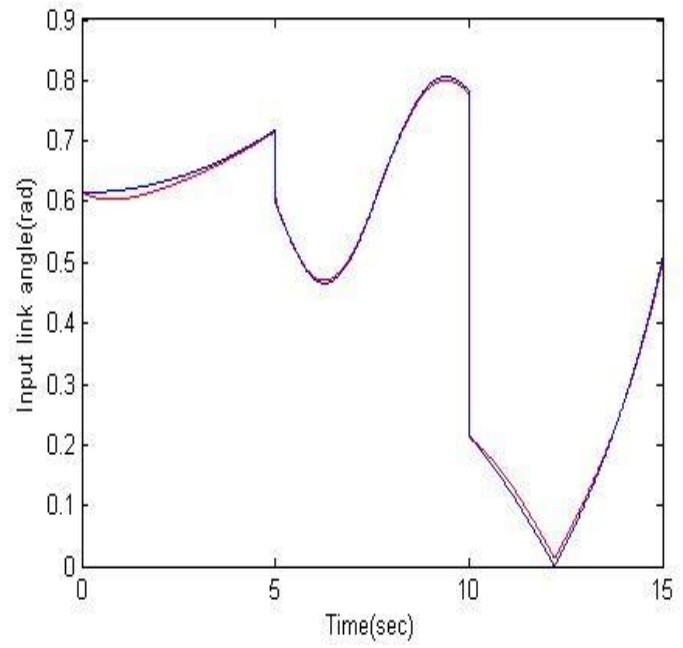

Figure 8 Obtained and desired input link angle for LQR based PID controller 


\section{Conclusion}

In this paper a 3-DOF manipulator is used which also knows as Maryland manipulator. LQR based PID control approach is implemented on this manipulator and results are analysed using MATLAB simulations. First, the system description and dynamics were introduced using Tsai and Stamper method. In the next section a DC motor model was introduced which act as an actuator for the given system. In the next section tuning methods for PID controller is discussed. The control approaches than were implemented using MATLAB software to validate them.

\section{Acknowledgment}

None.

\section{Conflicts of interest}

The authors have no conflicts of interest to declare.

\section{References}

[1] Stewart D. A platform with six degrees of freedom. Proceedings of the Institution of Mechanical Engineers. 1965; 180(1):371-86.

[2] $\mathrm{Li} \mathrm{Y}, \mathrm{Xu}$ Q. Design and development of a medical parallel robot for cardiopulmonary resuscitation. IEEE/ASME Transactions on Mechatronics. 2007; 12(3):265-73

[3] Shoham M, Burman M, Zehavi E, Joskowicz L, Batkilin E, Kunicher Y. Bone-mounted miniature robot for surgical procedures: concept and clinical applications. IEEE Transactions on Robotics and Automation. 2003; 19(5):893-901.

[4] Xu WL, Pap JS, Bronlund J. Design of a biologically inspired parallel robot for foods chewing. IEEE Transactions on Industrial Electronics. 2008; 55(2):832-41.

[5] Xu WL, Torrance JD, Chen BQ, Potgieter J, Bronlund JE, Pap JS. Kinematics and experiments of a life-sized masticatory robot for characterizing food texture. IEEE Transactions on Industrial Electronics. 2008; 55(5):2121-32.

[6] Liu K, Fitzgerald JM, Lewis FL. Kinematic analysis of a Stewart platform manipulator. IEEE Transactions on Industrial Electronics. 1993; 40(2):282-93.

[7] Bi ZM, Lang SY. Kinematic and dynamic models of a tripod system with a passive leg. IEEE/ASME Transactions on Mechatronics. 2006; 11(1):108-11.

[8] Ren L, Mills JK, Sun D. Trajectory tracking control for a 3-DOF planar parallel manipulator using the convex synchronized control method. IEEE Transactions on Control Systems Technology. 2008; 16(4):613-23.

[9] Luyben ML, Luyben WL. Essentials of process control. McGraw-Hill; 1997.

[10] Shahrokhi M, Zomorrodi A. Comparison of PID controller tuning methods. Department of Chemical \&
Petroleum Engineering Sharif University of Technology. 2013.

[11] Chu SY, Teng CC. Tuning of PID controllers based on gain and phase margin specifications using fuzzy neural network. Fuzzy Sets and Systems. 1999; 101(1):21-30.

[12] Cominos P, Munro N. PID controllers: recent tuning methods and design to specification. IEE ProceedingsControl Theory and Applications. 2002; 149(1):46-53.

[13] Moradi MH. New techniques for PID controller design. In IEEE conference on control applications 2003 (pp. 903-8). IEEE.

[14] Li Y, Ang KH, Chong GC. PID control system analysis and design. IEEE Control Systems. 2006; 26(1):32-41.

[15] Wang QG, Zhang Z, Astrom KJ, Chek LS. Guaranteed dominant pole placement with PID controllers. Journal of Process Control. 2009; 19(2):349-52.

[16] Duan XG, Deng H, Li HX. A saturation-based tuning method for fuzzy PID controller. IEEE Transactions on Industrial Electronics. 2013; 60(11):5177-85.

[17] Jayachitra A, Vinodha R. Genetic algorithm based PID controller tuning approach for continuous stirred tank reactor. Advances in Artificial Intelligence. 2014.

[18] Goodwin GC, Graebe SF, Salgado ME. Control system design. New Jersey: Prentice Hall; 2001.

[19] He JB, Wang QG, Lee TH. PI/PID controller tuning via LQR approach. Chemical Engineering Science. 2000; 55(13):2429-39.

[20] Dumlu A, Erenturk K. Trajectory tracking control for a 3-DOF parallel manipulator using fractional-order control. IEEE Transactions on Industrial Electronics. 2014; 61(7):3417-26.

[21] Tsai LW, Stamper R. A parallel manipulator with only translational degrees of freedom. 1996.

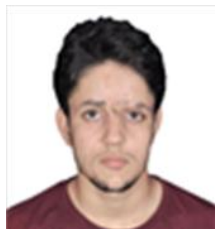

Gaurav Chaudhary was born in Jaipur, India in 1993. He received the B. Tech degree from RTU in 2013 and currently pursuing his Master's degree in Control System Engineering from NIT Kurukshetra. His area of interests includes theory of mechatronic, robotic system, fuzzy logic and fuzzy control, neural networks and their application to dynamic system and electrical engineering.

Email: ergaurav@outlook.com

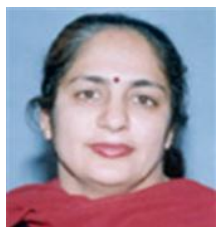

Jyoti Ohri received her $\mathrm{PhD}$ from NIT Kurukshetra in 2010. She is currently working as a professor with the department of electrical engineering, NIT Kurukshetra. Her research area of current interest are Robust and adaptive control, optimization, instrumentation 